\title{
Preliminary Analysis of Smart Grid Risk Index System and Evaluation Methods
}

\author{
Ruihua Liu \\ Sichuan Electric Vocational and Technical College, Sichuan Chengdu, China \\ Email: liuruihua1129@163.com
}

Received February, 2013

\begin{abstract}
Combined the purpose and requirements of security and stability economic operations of the smart grid, a more comprehensive, risk indicator system of smart grid is established from five aspects of the smart grid strategic risk, external risk, financial risk, compliance risk, operational risks. On this basis, it is conducted smart grid risk assessments by integrated of the use of Borda sequence value method of the original risk matrix and AHP (hierarchical analysis method), in order to assess risk facing the smart grid and enterprise development more comprehensively, objectively and systematically and conveniently, and prompt companies continue to reduce risk, improve economic efficiency, continuously improve the targeted improvement measures and continue to improve the level of grid development.
\end{abstract}

Keywords: Smart Grid; Information; the Borda Sequence Value Method; the Analytic Hierarchy Process

\section{Introduction}

In recent years, China's power grid construction has made great strides, basically meet the needs of economic and social development of the demand for electricity. Based on independent innovation, China speeds up the construction of UHV backbone frame for a strong smart grid [1-4] with characteristics of information, digitization, and automation, interactive. But in the situation of frequent natural disasters, the current complex economic and changing environment, electricity sales growth is slowing down; the risk of power grid is increasingly complex and diverse. It is necessary scientifically to assess the risks facing the grid development and enterprise development, determine the impact of the main risks in order to propose effective measures to reduce risk and promote the power grid development scientifically, healthy and sustainably.

Due to the complexity of the power system, the power grid risk is not likely to be characterized by a single indicator, it is necessary to use multiple risk indicators in order to more fully reflect the overall level of relationship from many different angles at the same time. Therefore, how to establish a scientific risk index system and taking targeted measures are crucial.

Based on the existing power grid risk assessment research [5-9], this paper put forward a more complete risk assessment index system for the smart grid, initially identified summarized, including strategic risk, external risk, financial risk, compliance risk, running risk about
19 indicators in five aspects. On this basis, describe the Borda sequence value method and AHP (Analytic Hierarchy Process) based on the original risk matrix, and fuse the two methods in the process of power grid enterprise risk assessment in order to play a certain role in guiding the development of smart grid.

\section{Smart Grid Risk Index System}

The construction and development of the smart grid is a complex system engineering with multi-objective, multidimensional and the whole process, accordingly, the risk assessment index system is also a multi-level index system. According to the role and requirements of the development of the smart grid, the risk index system is built from five aspects, grid enterprise strategic risks, external risk, financial risk, compliance risk, and operational risks, every aspect contains a number of subordinate indicators, in order to quantify from different angles. The five aspects constitute a whole system, which can fully and effectively reflected the risk facing the grid development and enterprise development, in order to reduce the major risk, improve the development of smart grid.

According to the correlation of risk and value chain management of power grid enterprise, initially identified and summarizes, the major risks include strategic risk, external risk, financial risk, compliance risk, and operational risks , the four aspects by analyzing the power grid enterprise within the external environment, internal interviews and expert assessment, and the architecture is 
shown in Table 1.

The risk indicators set is more targeted, can help power grid find main reason which affects grid development and enterprise development to grasp the direction of grid development, and targets research to propose risk reduction measures.

\section{Smart Grid Risk Assessment Methods}

\subsection{Original Risk Matrix Method}

Original risk matrix method primarily examine from the needs of the project and technology, based on the two aspects, analyze and identify whether there will be a risk, and take in some way.

Table 1. The architecture of power grid risk index system.

\begin{tabular}{|c|c|c|}
\hline \multirow{19}{*}{$\begin{array}{c}\text { Risk } \\
\text { indicators } \\
\text { for } \\
\text { smart } \\
\text { grid }\end{array}$} & \multirow{3}{*}{$\begin{array}{l}\text { Strategic } \\
\text { risk }\end{array}$} & Regulatory policy \\
\hline & & Transport capacity \\
\hline & & Mergers and acquisitions \\
\hline & \multirow{2}{*}{$\begin{array}{l}\text { Extemal } \\
\text { risk }\end{array}$} & natural disasters risk \\
\hline & & customer preferences \\
\hline & \multirow{3}{*}{$\begin{array}{l}\text { Financial } \\
\text { risk }\end{array}$} & Capital management risk \\
\hline & & cost control risk \\
\hline & & Electricity pricing risk \\
\hline & \multirow{4}{*}{$\begin{array}{l}\text { Compliance } \\
\text { risk }\end{array}$} & Contract Risk \\
\hline & & The risk of information \\
\hline & & Subsidiaries control \\
\hline & & project approval risk \\
\hline & \multirow{7}{*}{$\begin{array}{l}\text { Operational } \\
\text { risks }\end{array}$} & $\begin{array}{l}\text { Integrated scheduling } \\
\text { risks }\end{array}$ \\
\hline & & Electricity pricing risk \\
\hline & & material procurement risk \\
\hline & & human resources risk \\
\hline & & Security risks \\
\hline & & Technological innovation \\
\hline & & new market risk \\
\hline
\end{tabular}

Risk matrix method takes into account the risk impact and risk probability factors, and can conduct the most direct assessment of the risk factors that impact on the project. This method does not directly derived from expert opinion judgment matrix, but grading, through a more intuitive experience, judge by experts to quantify the level of risk impact and risk probability, determine prior impact on risk and risk probability, and then apply the Borda sort by analysis of the importance of various risk factors to assess the risk of the project. This method is feasible in specification decision-making process and can better integrate of the views of the groups, and therefore more and more widely appreciated. The concrete used in the risk assessment of the enterprise information project, we must first identify the potential risks of the project, identify, further analyze: assess risk potential impact on power grid, assess risk probability of occurrence to identify the risks in the risk matrix location, and then set the appropriate preventive measures or contingency plans. The likelihood of risk is shown in Table 2 .

\subsection{Borda Order Value Method}

Borda order value method introduces risk matrix to determine the level of risk, by sorting the risk of risk matrix. This method quantifies the level of risk and makes the final produce results at the same level of risk significantly less than the original risk matrix, which is conducive to the identification of key risk and more scientific for power grid.

On the other hand, the superiority of Borda order value method is that it can rate in roses-category based on multiple evaluation criteria of the importance of risk sort, which works as follow.

Assuming there is a total of $N$ risk, assuming a risk is $i$, $k$ is the one of the criteria (specifically applicable to the original matrix, two risk criteria: risk impact criteria and probabilistic risk criteria), and the level of the $i$ risk in the criteria $\mathrm{k}$ expresses as risk, so the Borda number of the risk $i$ is:

$$
b_{i}=\sum_{k=1}^{2}\left(N-r_{i k}\right)
$$

A risk Borda sequence value is the risk level, and the risk Borda sequence value is he number of the Borda large number of risk than the risk, so the Borda is much bigger and the risk level is much lower.

\subsection{Analytic Hierarchy Process}

Analytic Hierarchy Process (AHP, the Analytic Hierarchy Process) is a multi-objective decision-making method combined qualitative and quantitative evaluation. The basic idea of the method is a complex issue first decomposed into a certain level and a certain composition part, comparison and calculation of each component part of the piece, in order to obtain the weight of the different components, so as to focus on which integral part will be

Table 2. The architecture of power grid risk index system.

\begin{tabular}{cc}
\hline Risk level & $\begin{array}{c}\text { The likelihood of risk } \\
\text { (probability of occurring within one year) }\end{array}$ \\
\hline Lowest & 0.01 below \\
Lower & $0.01-0.3$ \\
low & $0.3-0.7$ \\
Higher & $0.7-0.9$ \\
Highest & 0.9 above \\
\hline
\end{tabular}


the basis of providing decision-making. Mathematics of the decision-making process to achieve a combination of qualitative and quantitative will be more intuitive. The main steps of the analytic hierarchy process are as follows:

\section{- $\quad$ Modeling}

Analyzing by AHP, in order to make the problem more conditioning, to build a hierarchical model is needed. The model can be clearly demonstrated the complex part of the problem. The level of the model can be divided into three categories:

One is the highest level, only one element, the ultimate goal of the plunge classification, in risk assessment, this element is the ultimate risk of information technology.

Second but the middle layer, criteria layer in the hierarchy, the middle layer are composed of several levels.

The third category is the lowest level, and also measures layer, the layer is used to implement measures and programs to achieve their goals. The most senior of the analytic hierarchy model established in the risk assessment of power grid enterprise are risk weights, the middle layer and the bottom is the index system of risk assessment information technology.

- Building a judgment matrix

Modeling the analytic hierarchy process, need to determine the importance of each factor to determine the importance of secondary and tertiary indicators, and can be drawn on the relative importance of the level, that is the weight, and then come to the overall risk weight of the index weights. With Arabic numerals 1-9 will determine quantifiable results form a judgment matrix, quantitative criteria such as Table 3 :

Judgment matrix of the structure is as follows:

$$
A=\left(a_{i j}\right)_{n \times m}=\left(\begin{array}{cccc}
a_{1} / a_{1} & a_{1} / a_{2} & \ldots & a_{1} / a_{n} \\
a_{2} / a_{1} & a_{2} / a_{2} & \ldots & a_{2} / a_{n} \\
\ldots & \ldots & \ldots & \ldots \\
a_{n} / a_{1} & a_{n} / a_{2} & \ldots & a_{n} / a_{n}
\end{array}\right)
$$

Table 3. The importance of quantitative criteria.

\begin{tabular}{cl}
\hline $\begin{array}{c}\text { Judging } \\
\text { system }\end{array}$ & \multicolumn{1}{c}{ two indexes evaluation rules } \\
\hline 1 & Equally important \\
3 & A slightly important than another \\
5 & Another obvious \\
7 & A strongly than the other \\
9 & Extremely important one than another \\
$2,4,6,8$ & Between the two adjacent judgments \\
Reciprocal & $\begin{array}{l}\text { The index i and j comparison deter- } \\
\text { mines } a_{i j}\end{array}$ \\
\hline
\end{tabular}

The matrix A is formed by pairwise comparison of the $\mathrm{n}$ number of risk factors, and the matrix elements of the quantized values is the importance of the element $i$ and $j$.

After building the judgment matrix based on expert scoring data, need for expert judgment matrix consistency test, if not meet the consistency test, need to adjust the matrix, last need to average expert data in accordance with the authority of experts level.

- Single-stage sort of risk factors and the consistency

Through various risk factors, determine the degree of importance of the various factors on levels of risk, and sort. The specific method is based on the matrix theory, the first judgment matrix is obtained feature vector $\mathrm{W}$, and then proceed to the normalization process, obtaining the weight.

Eigenvectors:

$$
W^{*}=\left(w_{1}^{*}, w_{2}^{*}, \ldots, w_{n}^{*}\right)^{T},
$$

and,

$$
w_{i}^{*}=\sum_{j=1}^{n} \frac{a_{i j}}{\sum_{i=1}^{n} a_{i j}}, i, j=1,2, \ldots, n
$$

Normalizing a treatment:

$$
\begin{aligned}
& W=\left(w_{1}, w_{2}, \ldots, w_{n}\right)^{T}, \\
& w_{i}=w_{i}^{*} / \sum_{i=1}^{n} w_{i}^{*}
\end{aligned}
$$

After calculating the eigenvectors of the judgment matrix, use eigenvectors to represent the impact of risk factors on the upper risk pairs. Check the consistency to judgment matrix, in order to ensure the reasonableness of the conclusions of the Analytic Hierarchy Process. Consistency of judgment matrix test method is as follows:

Firstly, obtain matrix eigenvalue $\lambda_{\max }$

Secondly, seeking the consistency index

$$
C_{I}=\left(\lambda_{\max }-n\right) /(n-1),
$$

it indicates that the judgment matrix has complete consistency, test end;

If $C_{I} \neq 0$, calculate the random consistency ratio $C_{R}=C_{I} / R_{I}, R_{I}$ value judgments average random consistency index of the matrix .

At last, by calculating, if $C_{R} \geq 0.1$, then the consistency of judgment matrix and risk factors sort results can be accepted, and if not, the consistency of the judgment matrix and risk factors Sort results can not be unacceptable and need to make the appropriate changes to the judgment matrix.

- $\quad$ Sort of total risk factors

Total risk factors sort is calculating a combination of weight relative to the total final goal the results for each 
focus all the elements by using results of the risk factors mentioned above, i.e. the risk factor for all levels on an element of risk importance weights weight. This step is carried out from the top down, can eventually obtain the combination weight of the overall corporate risk at the lowest level of power grid enterprise risk.

Considering that both of Borda value method and AHP have lack, integrate the two methods, we can make risk assessment more practical and more reasonable, and thus provide a more scientific basis for the next step to control risk. The specific method is:

Considering the likelihood of risk size and risk impact, first score risk and likelihood of occurrence probability for scoring and decided the risk level by risk matrix method, and then sort the importance of risk factors order by Borda sequence value method and inform the results to experts, after experts understanding of the relative importance of the risk situation, then pairwise comparison and get judgment matrix, comprehensively assess power grid risk by the traditional method of AHP-level analyze.

\section{Summary}

With the construction of the strong and smart grid in our country, information technology has been deepening and more sophisticated, this means a greater risk of consequential, and to assess various risk correctly will be able to make the decision-making to make quick and accurate decisions for the development of power grid enterprises by reducing the risk of occurrence or reduce the risk of occurrence which will bring negative effects and enable enterprises to more successful information technology.

The smart grid information risk index system covers five aspects of the grid enterprise: strategy risk, external risk, financial risk, compliance risk, operational risks. The assessment index system is relatively comprehensive and can fully reflect the grid risk in practical applications.

At the same time, assess risk of smart grid by the integration of the Borda sequence value method and on AHP (hierarchical analyze method), in order to be comprehen- sive, objective and systematic to assess, convenience for the grid enterprise early to detect the major risks facing the grid development, enable companies to continue to reduce risk, improve economic efficiency, continuing enhance the level of power grid development.

\section{REFERENCES}

[1] A. Ipakchi and F. Grid, "Albuyeh of the Future," IEEE Power and Energy Magazine, 2009. doi:10.1109/MPE.2008.931384

[2] J. M. Wang and T. Shi, "Construction of Evaluation Index System for Smart Grid,” East China Electric Power, Vol. 40, No. 2, 2012, pp. 0194-0196.

[3] Z. D. Wang, Y. Huang, ect., "Study on Evaluation Indexes of Power Grid Development,” Journal of Northeast Dianli University Natural Science Edition, Vol. 29, No. 4, 2009, p. 84.

[4] "Research Focuses and Advance Technologies of Smart Grid in Recent Years,” Chinese Science Bulletin, 2012, Vol. 5722, pp. 2879-2886.

[5] J. Gao and J. K. Wang, "Research on Communication Network Architecture of Smart Grid," Proceedings of 2012 International Conference on Future Electrical Power and Energy Systems, Hong Kong Education Society, Hong Kong:, 2012, 6.

[6] Z. S. Hua, B. G. Gong and X. Y. Xu, "A DS- AHP Approach for Multi-attribute Decision Making Problem with in Complete Inform Ation," Expert Systems with Applications, Vol. 34, No. 3. 2008.

[7] X. M. Niu, "Comparison of Several Regular Comprehensive Evaluation Method,” Statistics and Decision.

[8] C. Zhang, H. Z. Cheng, X. Xi, etc. "A Study of Distribution Network Feeding Modes Selection Based on Analytic Hierarchy Process and Fuzzy Comprehensive Evaluation,” Power System Technology, Vol. 30, No. 22, 2006, pp. 67-70.

[9] X. R. Chang, J. F. Xing and J. Zhang, “Dispatcher Training Evaluation Based On Multi-grade Fuzzy Comprehensive Evaluation Method,” Power System Technology, Vol. 29, No. 17, 2005, pp. 31-33. 